\title{
The Role of Growth Regulators in The Multiplication of Stevia Rebaudiana Bertoni Shoot and Callus Induction in Vitro
}

\author{
Zainab Hamed Abdul Rahim iD 1*, Lamia Khalifa Jawad ${ }^{2}$ \\ ${ }^{1,2}$ College of Agricultural Engineering Sciences- University of Baghdad \\ Corresponding Author: zainab.hamid1005@coagri.uobaghdad.edu.iq
}

\begin{abstract}
Article history:
Received 15 April 2021

Accepted 25 May 2021

keyword : stevia

rebaudiana bertoni, in vitro, micropropagation, callus.
\end{abstract}

\begin{abstract}
The research was conducted to investigate the effect of plant growth regulators on the vegetative multiplication of the Stevia plant shoot and the induction of callus from it. The results indicated that the interaction between $2.0 \mathrm{mg}$. L-1 BA with $0.5 \mathrm{mg}$. L - 1 Kin gave the highest rate number of shoot with 6.32 branches and the highest average of leaves number Were 9.60 leaves compared to the lowest average for the number of shoot and leaves Were 1.40 shoot and 3.80 leaves respectively. As for the length of the shoot, the interaction between $(1.0 \mathrm{mg}$. L-1 BA and $0.5 \mathrm{mg}$. L-1 Kin) gave the highest average shoot length $4.31 \mathrm{~cm}$ compared to the control which gave $2.20 \mathrm{~cm}$. in connection with the callus induction, the concentration $3 \mathrm{mg}$. L-1 of NAA gave the highest percentage of callus induction from leaves $100 \%$, and the lowest mean of days that for callus initiation was 9 days compared to the control which reached to 20 days. As for the wet and dry weights of callus tissue, the interaction between $2.0 \mathrm{mg}$. L-1 NAA and $0.5 \mathrm{mg}$. L -1BA gave the highest wet weight rate $3.68 \mathrm{~g}$ and the average dry weight was $0.31 \mathrm{~g}$ compared to the control which gave the lowest rate $0.95 \mathrm{~g}, 0.08 \mathrm{~g}$ respectively.
\end{abstract}

\section{Introduction}

nowadays Stevia rebaudiana Bertoni is one of the most plants that has received interest and that due to Its medical importance and its commercially use as non-caloric sweetener for diabetic patient, also stevia leaves are also used in weight-loss programmes in order to their ability to decrease the appetite for sweet and fatty foods .Stevia rebaudiana Bertoni belongs to the family Asteraceae, and its natural habitat extends from the south western United States to Paraguay, Mexico and Brazil forests, and it grows in tropical and subtropical areas. The leaves contain terpenoid glycosides, the most important of them are the compounds of stevoside and ribodioside $\mathrm{A}$, and the "stevia" plant is characterized as being sweeter than raw sugar 300-250 and 450-350 times (Gerami et al. 2017). Stevia leaves are a source of diploid terpenes glycosides such as steviolbioside, rebaudioside A, B, C, D, E, F, rubsoside, dulcoside and stevioside (Starratt et al. 2002). It is worth mentioning that stevoid and other bi-terpenoid glycosides are used in several types of food, such as sauces, vegetable pickles, dried seafood, drinks, chewing gum and ice cream (Icecream) in addition to toothpaste and mouthwash. Stevia extract and steviod uses in food factories in United states, Brazil , Korea and Japan (Mizutani and Tanaka 2002 ; Choi et al. 2002). Stevia seeds appear a very low germination percentage beside that vegetative propagation is limited by lower number of individuals that make Tissue culture and vitro micropropagation from shoot tip and leaf is the only rapid process for propagation of stevia plant, therefore, the aim of this study was to investigate the impact of plant-growth regulators and to determine the optimal plant part on multiply the branches of the stevia plant and establish cultures of callus tissue from them.

\section{Materials and Methods}

This research was carried out in the postgraduate laboratory of Agricultural Sciences Engineering College/Baghdad University, The used

* https://orcid.org/0000-0003-4280-2821 
seeds of the Stevia rebaudiana Bertoni plant were imported from the Spanish company Semillas fitto, The seeds were washed by soap to remove the dust then they were transferred to the Laminar air flow cabinet device, after that they were submerged with a concentration of $6 \%$ of $\mathrm{NaOCl}$ for 15 minutes, then washed with distilled water three times, to ensure that it gets rid of the sterilizing materials, then planted in culture tubes with solid MS medium free of growth regulators and incubated at a temperature of $25 \pm 2^{\circ} \mathrm{C}$ in the dark for a week, and after germination it were exposed to the lighting 1000 lux for 16 hours and 8 hours of darkness, and after obtaining the seedlings, they were cut and the stem nodes was taken. It was planted on the same previous medium and under the same conditions, to obtain the branches for the multiplying stage. (Murashige and Skoog, 1962) (MS) medium is the most extensively used for the vegetative reproduction of many plant species in vitro. We used medium supprlemented with 30 g.L-1of sucrose, and complete the volume to $600 \mathrm{ml}$ by distilled water, and it was adjusted its $\mathrm{pH}$ to the value 5.7 by adding drops of Sodium hydroxide $(\mathrm{NaOH})$ or hydrochloric acid $(\mathrm{HCl})$ as standard solution, then complete the volume to $1000 \mathrm{ml}$, then add $7 \mathrm{~g}$. liter- 1 of agar, the ingredients of the nutrient medium were heated on the Hot Plate Magnetic Stirrer for the for dissolving the components of nutrient medium in gredients media to be homogeneous, then it was distributed in screw glass tubes with dimensions of 85 x $28 \mathrm{~mm}$, by $10 \mathrm{ml}$ per tube, after that it was sterilized with Autoclave at $121^{\circ} \mathrm{C}$ and a pressure at $1.04 \mathrm{~kg}$. (Cm2) -1 for 15 minutes, after sterilization the tubes were placed at room temperature to harden, After that, we separated the stem nodes with a length of 1 $\mathrm{cm}$ from the seedling which were obtained from initiation stage, and transferred to test tubes which containing new media for multiplying vegetatively them, and the MS medium was used cytokinein (BA) at the concentrations $0,1.0,2.0,3.0 \mathrm{mg}$.L-1and with concentrations $0,25.0,5.0,1.0 \mathrm{mg}$. L-1 of kinetin $(\mathrm{Kn})$ by ten replications per treatment to study the effect of cytokinein on the multiplication of implants by calculating a rate number of doubled branches, the average length and the number of leaves for each treatment after four weeks of incubation. after that we choised the best result from the multiplication experiment which were the inter node shoot tip, leaves and nodes, to used it in induced the callus, these parts were planted in the MS nutrient medium which contains different concentrations of the growth regulator NAA that included $0,1.0,2.0,3.0,4.0 \mathrm{mg} .1-1$ and the plant parts were incubated to induce callus in complete darkness with ten replications of each treatment to study its effect on callus initiation by measuring the percentage of callus induction and the number of required days.

The results were recorded after four weeks of planting, according to the results we found that the leaves were the best response to the initiation of callus relative to the percentage of callus induction so we exluded the rest of the plant parts, where the callus was taken from the induction phase the result of cultivation in MS medium was added to NAA at a concentration of $3.0 \mathrm{mg}$. L-1 NAA for includ the perpetuation experiment, as it was planted on different combinations of growth regulators, oxin NAA concentrations were 2.0,1.0,0 and 3.0 mg.1-1, while cytokinin BA concentrations were 0,25.0,5.0,1.0 mg.1-1, the results were taken after four weeks of planting, represented by measuring the wet and dry weights of callus. all trial data were analyzedusing Completely Randomized Design (CRD) and use 10 replicat per treatment, The averages were compared according to the LSD test and at the $5 \%$ probability level.

\section{The effect of BA and Kin and their Interaction on the Mean Number of Stevia Plant Branches in Vitro After Four Weeks of Planting.}

The results in table (1) indicated that added BA to the media of stevia multiplicating branches, led to a significant increase in the average of formed branches, reaching to $2.0 \mathrm{mg}$. L-1 BA, which gave the highest rate of number of formed branches 5.16 branches, while the comparison treatment that gave 2.10 branches as for the effect of Kin concentration we noticed that there is a significant effect on the average of branches, as it increased significantly and the gave $0.5 \mathrm{mg}$. L- 1 concentration 0.54 .65 branches in addition to the number of branches decreased by increasing the concentration of Kin, where the concentration $1.0 \mathrm{mg}$. L-1 was given the lowest rate of branches as for the interaction, we noted that the effect was also significant in the number of branches, where the highest number of brunch was in $2.0 \mathrm{mg}$. L-1 BA and $0.5 \mathrm{mg}$. L - $1 \mathrm{Kin}$ treatment which reached to 6.32 branches with a defferent significantly compared to control which was 1.40 branches 
Table 1. The effect of BA and Kin and their interaction on the mean number shoot of stevia in vitro after four weeks of planting

\begin{tabular}{|c|c|c|c|c|c|}
\hline \multirow{2}{*}{ Average } & \multicolumn{4}{|c|}{ Concentration Kin mg. $\mathrm{L}^{-1}$} & \multirow{2}{*}{$\begin{array}{c}\text { Concentration BA } \\
\text { mg. } \mathrm{L}^{-1}\end{array}$} \\
\hline & 1.0 & 0.5 & 0.25 & 0.0 & \\
\hline 2.10 & 2.80 & 2.20 & 2.00 & 1.40 & 0.0 \\
\hline 4.08 & 2.50 & 4.40 & 5.00 & 4.40 & 1.0 \\
\hline 5.16 & 4.04 & 6.32 & 5.50 & 4.80 & 2.0 \\
\hline 4.47 & 3.60 & 5.68 & 4.60 & 4.00 & 3.0 \\
\hline 0.67 & \multicolumn{5}{|c|}{$\operatorname{Lsd} 0.05(B A)=1.356$} \\
\hline$-\cdots$ & 3.24 & 4.65 & 4.28 & 3.65 & Average \\
\hline \multicolumn{6}{|c|}{ Lsd $0.05(\mathrm{Kin})=0.678$} \\
\hline
\end{tabular}

Effect of BA and Kin and their Interaction on The Average Number Leaves of Stevia Plant in Vitro After Four Weeks of Planting.

The results in Table (2) indicated that $\mathrm{BA}$ the concentration $2.0 \mathrm{mg}$. L-1 BA had a significant effect on increasing the average number of leaves which reached 7.53 leaf. branch -1 compared to the control 4.60 leaf. branch -1, and we noticed that Kin

Table 2. Effect of BA and Kin and their interaction on the average leaves number of stevia plant in vitro after four weeks of planting

\begin{tabular}{|c|c|c|c|c|c|}
\hline \multirow{2}{*}{ Average } & \multicolumn{4}{|c|}{ Concentration Kinmg. L ${ }^{-1}$} & \multirow{2}{*}{$\begin{array}{l}\text { Concentration } \\
\text { BAmg. L }\end{array}$} \\
\hline & 1.0 & 0.5 & 0.25 & 0.0 & \\
\hline 4.60 & 5.40 & 5.20 & 4.00 & 3.80 & 0.0 \\
\hline 5.93 & 4.31 & 6.13 & 7.08 & 6.20 & 1.0 \\
\hline 7.53 & 5.70 & 9.60 & 8.30 & 6.50 & 2.0 \\
\hline 6.63 & 5.20 & 8.30 & 6.90 & 6.14 & 3.0 \\
\hline 1.15 & \multicolumn{5}{|c|}{ Lsd 0.05 (BA) 2.306} \\
\hline ---- & 5.15 & 7.31 & 5.76 & 5.66 & Average \\
\hline & & Lsd & $=1.1$ & & \\
\hline
\end{tabular}

at all concentrations had an effect in increasing the average number of leaves compared to control, but concentration $0.5 \mathrm{mg}$. L-1 gave the highest average number of leaves and by a significant effect compared to other treatment which was 7.31 leaf. branch-1, and for the interaction, the treatment $(2.0$ mg. L-1 BA and $0.5 \mathrm{mg}$. L-1 Kin) had a significantly effect compared to the rest treatments which was 9.60 leaf. branch -1 and the lowest value was in contrp 3.80 leaf. Branch 


\section{The Effect of BA and Kin and their Interaction on The Average Branch Length $(\mathbf{c m})$ of Stevia Plants in Vitro After Four Weeks of Planting.}

We Noted from the results in Table 3 that the addition of different concentrations of BA led to a significant decrease in the ex vivo shoot length of stevia in vitro except the concentration of $1.0 \mathrm{mg}$. $\mathrm{L}-1$, there are not significant differences between it (3.09) and the control (3.36). As for Kin, the addition Kin by concentration (0.5-0.1) mg.L-1had the highest average length of shoot $(2.80-2.49) \mathrm{cm}$ Respectively , with a significant difference compared to control which was $1.77 \mathrm{~cm}$, the interaction had a significant affect in increasing the average length of shoot, which reached to $4.31 \mathrm{~cm}$ by $(1.0 \mathrm{mg}$. L-1 BA with $0.5 \mathrm{mg}$. L-1 Kin) treatment, while the lowest average length was 1.00 $\mathrm{cm}$ in the medium containing $2.0 \mathrm{mg}$. L-1 BA with 1.0 mg. L -1 Kin.

Table 3. The effect of BA and Kin and their interaction between on the average shoot length (cm) of stevia plants invitro after four weeks of planting

\begin{tabular}{|c|c|c|c|c|c|}
\hline \multirow{2}{*}{ Average } & \multicolumn{4}{|c|}{ Concentration Kin mg. L-1 } & \multirow{2}{*}{$\begin{array}{c}\text { Concentration BA } \\
\text { mg. L }^{-1}\end{array}$} \\
\cline { 2 - 5 } & 1.0 & 0.5 & 0.25 & 0.0 & 0.0 \\
\hline 3.36 & 3.86 & 3.77 & 3.62 & 2.20 & 1.0 \\
\hline 3.09 & 3.93 & 4.31 & 2.57 & 1.56 & 2.0 \\
\hline 1.43 & 1.00 & 1.64 & 1.44 & 1.64 & 3.0 \\
\hline 1.42 & 1.16 & 1.47 & 1.38 & 1.66 & \\
\hline 0.60 & \multicolumn{5}{|c|}{ Lsd 0.05 (BA) $=0.60$} \\
\hline--- & 2.49 & 2.80 & 2.25 & 1.77 & Average \\
\hline \multicolumn{7}{|c|}{ Lsd 0.05 (kin) $=1.20$} \\
\hline
\end{tabular}

We conclude from the results of Table (1) and (2) that BA was more effective than Kin in increasing the rate of the branches and leaves number and in causing the multiplication process,perhaps that due to the composition of this cytokinein molecule and the number of double bonds which it has in its side chain, it contains three double bonds on the contrary of Kintine, as it contains only two bonds, in addition to the benzyl ring, which made BA one of the most prominent cytokines used widely in plant propagation (Abdul,1987). Also BA is considered a stable compound that because it is not easily degraded and has high efficiency in breaking the apical dominance which leads to expanding Xylem transport vessels and sieve tubes for phloem tissue, prevent degradation of chlorophyll, stimulate cell division and increase nucleic acid production (Mok et al. 2000 and Schmulling, 2004). These results are in agreement with (AbdEl-Motaleb et al,. 2013); (AbdEl-Razak et al. 2014); (Tufail et al. 2019); (Aziz and ALtaweel, 2019). Also the results as table No. (3) indicated the importance of cytokinins in increasing the length of branches, we noticed the superiority treatment $(1.0 \mathrm{mg}$. L-1 BA with $1.0 \mathrm{mg}$.
L-1 KIN) in increasing the average branch length which reached $3.93 \mathrm{~cm}$, and this is due to the role played by these two cytokinins in stimulating cell division and growth (Al-Khafaji, 2014).

\section{The Effect of Different Concentrations of NAA Auxin on The Percentage of Callus Induction of Stevia in Vitro.}

Table (4) showed the effect of different concentrations of NAA on the percentage of callus induction from the different plant parts of the stevia plant leaf, shoot tip, node and internode, the results indicated that concentration $3.0 \mathrm{mg}$. Liter-1 of NAA gave the highest percentage of callus induction for all plant parts cultivated leaf, shoot tip, node and internode $(100,80,70,80 \%)$ respectively compared to the rest concentrations, in another hand the control treatment gave the lowest percentage of callus induction of $(40,40,20,30 \%)$ respectively, also the leaf gave the highest percentage of callus induction of $100 \%$ compared to all plant parts 
Table 4. Effect of different NAA auxin concentrations on the percentage of callus induction of stevia in vitro

\begin{tabular}{|c|c|c|c|c|}
\hline Inter node & node & Shoot tip & Leaf & $\begin{array}{c}\text { Concentration } \\
\text { NAA mg. L }\end{array}$ \\
\hline 30.00 & 20.00 & 40.00 & 40.00 & $\mathbf{0 . 0}$ \\
\hline 60.00 & 50.00 & 50.00 & 60.00 & 1.0 \\
\hline 70.00 & 60.00 & 70.00 & 80.00 & $\mathbf{2 . 0}$ \\
\hline 80.00 & 00.70 & 80.00 & 100.00 & $\mathbf{3 . 0}$ \\
\hline
\end{tabular}

\section{The Effect of NAA Auxin Concentrations on The Number of Required Days for The Initiation of Callus Tissue from Different Plant Parts of The Stevia Plant in Vitro.}

The results in table (5) indicated that the addition of different concentrations of the growth regulator NAA to the culture medium led to a decrease in the number of required days for the initiation of callus tissue from the different plant parts of the stevia plant, the best concentration was $3.0 \mathrm{mg}$. L-1 NAA in decrease the period to induce callus tissue from the leave and the internode, it was $(9,12)$ days respectively, while the control gave the longest period of 20 days. in leave and 18 days. in internode. The induction of callus tissue from the shoot tip at the concentration $2 \mathrm{mg}$. L-1 NAA was 14 days that the best result compared to control which reached to 25 days. but the best treatment induction the callus fromnode in shorter period was $1.0 \mathrm{mg}$. L-1 NAA (10) days compared to control which was 16 days.

Table 5. The effect of NAA auxin concentrations on the number required days for the initiation of callus tissue from different plant parts of the stevia plant in vitro

\begin{tabular}{|c|c|c|c|c|}
\hline Inter node & Node & Shoot tip & Leaf & $\begin{array}{c}\text { Concentration } \\
\text { NAA mg. } \mathbf{L}^{-1}\end{array}$ \\
\hline 18.00 & 16.00 & 25.00 & 20.00 & $\mathbf{0 . 0}$ \\
\hline 15.00 & 10.00 & 18.00 & 14.00 & $\mathbf{1 . 0}$ \\
\hline 13.00 & 11.00 & 14.00 & 12.00 & $\mathbf{2 . 0}$ \\
\hline 12.00 & 12.00 & 15.00 & 9.00 & $\mathbf{3 . 0}$ \\
\hline 14.00 & 14.00 & 17.00 & 16.00 & 4.0 \\
\hline 2.285 & 3.258 & 2.860 & 2.208 & L.S.D. 0.05 \\
\hline
\end{tabular}

The induction of callus from different plant parts of the stevia plant depends on the used factors in agriculture, including the type of plant part and its source, the type and concentration of added growth regulators to the nutrient medium and genotype (Savita et al. 2010) so the balance in the concentrations of growth regulators in the nutritional medium leads to the induction of different proportions of callus, and the speed of callus induction also depends on the concentration of endogenous growth regulators in the cultivated plant part (Zakaria et al., 2010).
Table 6. Effect of BA and NAA Auxin and Their Interaction on Average Wet Weight (gm) of Leaf Stevia Callus in Vitro.

The results in table (6) showed that addition of NAA to the medium led to a significant increase in the wet weight of the leaf induced callus compared to the auxin-free treatment. The concentration 2.0 mg. L-1 of NAA was the most effective, by $2.48 \mathrm{~g}$ wet weight of of callus with a significant increase in the average wet weight of callus. And when the concentrations $0.5 \mathrm{mg}$. L-1 and 1.0 of BA was added to the nutient medium, they gave the highest 
average wet weight of callus $(2.12,2.10) \mathrm{g}$ respectively. The effect of the interaction between NAA and BA was significant in increasing the wet weight rate of callus, and the treatment $(2.0 \mathrm{mg}$.L-
1NAA with 0.5 mg.L-1 BA) had the highest average Wet weight $3.68 \mathrm{~g}$ compared to the control treatment, which gave the lowest Wet weight rate for callus of $0.95 \mathrm{~g}$.

Table 6.Effect of BA and NAA auxin and their interaction on average wet weight ( $\mathrm{gm}$ ) of leaf stevia callus in vitro

\begin{tabular}{|c|c|c|c|c|c|}
\hline \multirow{2}{*}{ Average } & \multicolumn{4}{|c|}{ Concentration BA mg. L } & $\begin{array}{c}\text { ConcentrationNA } \\
\text { A mg. L }^{-1}\end{array}$ \\
\cline { 2 - 5 } & 1.0 & 0.5 & 0.25 & 0.0 & 0.0 \\
\hline 1.79 & 2.70 & 1.83 & 1.66 & 0.95 & 1.0 \\
\hline 1.85 & 1.50 & 1.77 & 2.31 & 1.82 & 2.0 \\
\hline 2.48 & 2.84 & 3.68 & 1.92 & 1.48 & 3.0 \\
\hline 1.27 & 1.35 & 1.20 & 1.58 & 0.93 & Average \\
\hline 0.55 & \multicolumn{7}{|c|}{ Lsd 0.05 (BA) $=0.55$} \\
\hline
\end{tabular}

Table 7. Effect of BA and NAA Auxin and their Interaction on Average Dry Weight (gm) of Leaf Stevia Callus in Vitro.

The results in table (7) Indicated that the addition of NAA to the medium led to a significant increase in the dry weight of the leaf induced callus compared to the auxin-free treatment. The concentration $2.0 \mathrm{mg}$.L-1 of NAA was the most effective by $0.19 \mathrm{~g}$ dry weight of callus. The medium free of NAA was the lowest dry weight $0.14 \mathrm{~g}$, and a significant increase in the average dry weight of callus $(0.22) \mathrm{g}$ was obtained when BA was added to the nutient medium by the concentration $0.5 \mathrm{mg}$. L-1. The effect of the interaction between NAA and BA was significant in increasing the dry weight rate of callus, but the treatment $(2.0 \mathrm{mg}$. L1 NAA with $0.5 \mathrm{mg}$. L-1 BA) was the highest average dry weight $0.31 \mathrm{~g}$ compared to the control treatment, which gave the lowest dry weight rate for callus of $0.08 \mathrm{~g}$.

Table 7. Effect of BA and NAA auxin and their interaction on average dry weight (gm)

\begin{tabular}{|c|c|c|c|c|c|}
\hline \multirow{2}{*}{ Average } & \multicolumn{4}{|c|}{ Concentration BA mg. $\mathrm{L}^{-1}$} & \multirow{2}{*}{$\begin{array}{c}\text { Concentration NAA } \\
\text { mg. } \mathrm{L}^{-1}\end{array}$} \\
\hline & 1.0 & 0.5 & 0.25 & 0.0 & \\
\hline 0.14 & 0.15 & 0.19 & 0.13 & 0.08 & 0.0 \\
\hline 0.16 & 0.12 & 0.18 & 0.15 & 0.19 & 1.0 \\
\hline 0.19 & 0.15 & 0.31 & 0.12 & 0.17 & 2.0 \\
\hline 0.15 & 0.14 & 0.17 & 0.13 & 0.13 & 3.0 \\
\hline 0.06 & \multicolumn{5}{|c|}{ Lsd $0.05(\mathrm{BA})=0.061$} \\
\hline \multirow[t]{2}{*}{----} & 0.14 & 0.22 & 0.14 & 0.15 & Average \\
\hline & \multicolumn{5}{|c|}{ Lsd $0.05($ kin $)=0.123$} \\
\hline
\end{tabular}

Generally, the response of the plant cuttings depends on the internal level and amount of absorption of growth regulators to reach an appropriate level for formating and growth of callus, and the leaves are considered to have a high capacity for callus formation and a good source in plant tissue culture. in fact, the polarity of the cells changes (loss of differentiation) for some of them, and they can continue to divide and expand forming callus tissue. The increase in the fresh and dry weight of callus is a reflection of changes in the various contents of its cells which depend on its growth nutrient medium that mainly depends on the added growth regulators. Generally, the process to cell division is accompanied by an increase in the important contents to sustain division and growth such as carbohydrates, proteins and amino acids with internal changes that lead To cell division and then specialization (Serma et al. 2011; PawelecKasprzyh et al., 2015) and the phenomenon of 
callus formation stimulated by growth regulators gives strong evidence for the process of specializing plant cells and not losing their cell potentialities (Saini et al., 2010). As for the high levels of auxins and cytokinins, they cause a decrease in the growth and division rates of cells due to the disruption of vital processes within the tissues, as a result of the hormonal imbalance, which leads to the formation of ethylene, which in turn inhibits the metabolic activities and decreases the rates of division and growth of plant parts (Devlin and Withman, 1983) and these findings are in agreement with those of (Masri et al. 2019) and (Blinstrubiene et al, 2020)

Fig1. Callus on the (MS) medium supplement with (2.0 mg. L-1 NAA with $0.5 \mathrm{mg} . \mathrm{L}-1 \mathrm{BA})$

\section{Conclusions}

The possibility of Multiplication of the Stevia plant by culure plant tissues and in large numbers from the culure of single nodes, Addition of, of both cytokinin (BA) and kinetin (KIN) are necessary to obtain the best Multiplication, and the addition of benzyl adenine BA by concentration of $2.0 \mathrm{mg}$. L1 to the MS medium interaction with kinetin $0.5 \mathrm{mg}$. L-1 to give a significant increase in the number and growth of Shoot. Moreover the leaves gave the highest percentage of callus tissue induction on the medium supplied $3.0 \mathrm{mg}$. L-1 NAA.

\section{Conflict of interests}

There is no conflict of interest between authors

\section{Acknowledgements}

Thanks to the supervisor Dr. Lamiya Khalifa Jwad and to the staff of Plant Tissue Culure Laboratory, Department of Horticulture and Landscape Engineering, college of Agricultural
Engineering Sciences / University of Baghdad, for their assistance in carrying out this research

\section{References}

Abd EL-Motaleb, M.A., M.S.A. El-Hady. M.A. El-Kholy and A., Badr. 2013. In vitro propagation of Stevia rebaudiana Bertoni in Egypt. Journal of Applied Sciences Research, 9(8): 4597-4605.

Abdul, K. S.1987. Plant growth regulators. part One. Ministry of Higher Education Education Iraq.

Abdul Razak, U.N.A.A., C.B. Ong. T.S. Yu and L.K. Lau. 2014. In vitro micropropagation of Stevia rebaudiana Bertoni in Malaysia. Brazilian Archives of Biology and Technology, 57(1):23-28.

Al-Khafaji, Z. M and H. M. Abu Al-Maaly. 2013. Multiplication reactions and primer design. University of Baghdad, Ministry of Higher Education and Scientific Research, Republic of Iraq. 
Aziz, R.A and S.K. Al-Taweel. 2019. Effect of plant growth retadants on stevia (Stevia rebaudiana Bertoni) acclimatization produced in vitro. Plant Archives, 19 (1): 1275-1284.

Blinstrubien e, A., N. Burbulis, N. Juskeviciut eand R.ukiene .2020. Effect of Growth Regulators on Stevia rebaudiana Bertoni Callus Genesis and Influence of Auxin and Proline toSteviol Glycosides, Phenols, Flavonoids Accumulation, and AntioxidantActivity In Vitro. Molecules 25: 27 $-59$.

Choi, Y. H., I. Kim, K. D. Yoon, S. J. Lee, C. Y. Kim and K. P. Yoo. 2002. Supercritical fluid extraction and liquid chromatographicelectrospray mass spectrometric analysis of stevioside from Stevia rebaudiana leaves. Chromatographia 55(9 - 10): 617-620.

Devlin, R.M. and F. H. Witham. 1983. Plant Physiology. (4thed) Wadsworth Publishing Company Belmont California.

Gerami, M., H. Abbaspour, V. Ghasemiomran and H. Pirdashti. 2017. Effects of Ethyl Methane sulfonate on Morphological and Physiological Traits of Plants Regenerated From Stevia (Stevia rebaudiana Bertoni) Calli., Applied Ecology and Environmental Research 15 (3): 373-385.

Kasprzyk - Pawelec , A., J. Pietrusiewicz, E. Szczuka and M. Curie-Sklodowska. 2015. In vitro regeneration induced in leaf explants of Citruslimon L. Burm cv. 'Primofiore' University in Lublin Acta Sci. Pol. HortorumCuhure , 14 (4) ; 143-153 .

Masri, M.I., M.M.M., Amein, R.M.A. Aziz, and Sayed, D.O. Sayed. 2019. Cllogenesis and plant regeneration via in vitro culture of stevia rebaudlana explants . Egypt. J. Plant Breed. 23(1):65- 76 .

Mizutani, K., O. Tanaka. 2002. Use of Stevia rebaudiana sweeteners in Japan. In: A. D. Kinghorn (Ed.), Vol.19, pp. 178-195. Stevia, the Genus Stevia. Medicinal and Aromatic Plants Industrial Profile London: Taylor and Francis.

Mok, D.W.S. 2000. Cytokinins: biosynthesis, metabolism and perception. In Vitro Cell. Dev. Biol. Plant 36:102-107.
Murashige, T. and Skoog, F. 1962. A revised medium for rapid growth and bio assays with tobacco tissue cultures. Physiologia Plantarum, 15(3):473-497.

Saini,H.K., M.S. Gill and M.I.S. Gill. 2010. Direct shoot organogenesisand plant regeneration in rough lemon (Citrus jambhiriLush.). Ind. J. Biotech., 9, 419:423.

Serma , C., A. Borthakur, S. Singh, M.K. Mod and P. Sen .2011. Efficient in vitro plant regeneration from cotyledonary explants of Citrus reticulataL. Blanco. Ann. Biol. Res., 2(6): 341-348 .

Savita , V.,G.S. Virk and A.Nagpal . 2010. Effect of explant type and different plant growth regulators on callus induction and plantlet regeneration in CitrusjambhiriLush. Environ. We Int. J. Sci. Tech., 5, 97-106.

Schmulling, T. 2004. Cytokinins in Encyclopedia of Biological Chemistry. Academic Press/ Elsevier Science

Starratt, A. N., C. W. Kirbyb, R. Pocsa and J. E. Brandle. 2002. Rebaudioside F, a diterpene glycoside from Stevia rebaudiana. Phytochemistry 59:367.

Tufail , M.B., G. Mustafa . F. A. Joyia, Mushtaq, Z. Ghazala and Khan, M. S. 2019. Establishment of Proficient in vitro mass multiplication and regeneration system for enhanced production of stevioside and rebaudiosideA in stevia rebaudlana. The Journal of Animal \& Plant Sciences, 29(3): 796-802.

Zakaria, Z., S. Zakaria ,H. Kalid and M.A.M . Ishak . 2010. Induction of callus formation from different Parts of Citrus grandis (Osbeck) Flowers .Bio. 17 (1) :1-7. 